Part of Journal of Research of the National Bureau of Standards, Volume 26, February 1941

\title{
DISTRIBUTION OF OZONE IN THE STRATOSPHERE: MEASUREMENTS OF 1939 AND 1940
}

\author{
By W. W. Coblentz and R. Stair
}

\section{ABSTRACT}

Continuing the measurements of ultraviolet solar radiation intensities in the stratosphere made in 1937 and 1938 (RP1207), in this paper a description is given of similar measurements made with improved apparatus in the summer of 1939 and 1940 .

The apparatus that was transported aloft by means of unmanned balloons consisted of the following elements: (1) a photoelectric cell and filter radiometer, connected with a balanced amplifier, relaxation oscillator, and radio transmitter for measuring the ultraviolet intensities; (2) a radio-operated barometer, giving the heights attained by the apparatus; and (3) an electrolytic resistor for measuring the ambient temperature of the ultraviolet intensity meter.

The audio-frequency modulated radio wave, giving (1) the intensity of the incident ultraviolet solar radiation, (2) the elevation of the apparatus, and (3) the temperature of the ultraviolet meter, was received and graphically recorded at a fixed ground station (RP1075).

In three successful flights made in June 1939, and in two similar flights made in 1940 , the ultraviolet radiometer attained heights ranging from about 78,000 to about $88,000 \mathrm{ft}(23$ to $27 \mathrm{~km})$. From the observed change in filter transmissions of ultraviolet solar radiation with elevation, it is deduced that the apparatus passed through 65 to 70 percent of the ozone (and other ultraviolet-absorbing constituents, if any, in the upper atmosphere), the most of which is localized in a layer extending from 15 to $27 \mathrm{~km}$, with a wide maximum of concentration at a height of about 24 to $25 \mathrm{~km}$, above the earth's surface. At the highestelevation attained by the instruments, the intensity of the ultraviolet solar radiation of wavelengths shorter than 3132 A was 10 to 12 times that observed at sea level.

\section{CONTENTS}

I. Introduction

1. Tests with the new type radio tubes

II. Exploration of the vertical distribution of ozone in the stratosphere... 163

1. Notes on the stratosphere balloon flights $\ldots \ldots \ldots \ldots \ldots$

III. Evaluation of the ultraviolet intensity measurements $\ldots \ldots \ldots 5$

1. Effect of temperature on the ultraviolet measurements _._. _.. 166

2. The extraterrestrial ultraviolet solar spectral-energy curve

3. Exposition of data

IV. References and notes

\section{INTRODUCTION}

In a previous communication [1] ${ }^{1}$ a description was given of the results obtained in June 1938 in measuring ultraviolet solar intensities, and thereby determining the vertical distribution of atmospheric ozone, at various elevations above the earth's surface. Readers interested in the subject are referred to this and other papers for a description of the instruments used $[1,6,7]$; the methods of measure-

\footnotetext{
1 Figures in brackets indicate the literature references and notes at the end of this paper.
} 
ment, and reduction of observations; and for a discussion of the preliminary measurements made in June $1937[5,6]$.

For clarity in exposition of the herein described data, it is relevant to record that an ultraviolet-intensity meter, consisting of a photoelectric cell and filter radiometer connected with an audio-frequency generator and radio transmitter, is transported aloft by means of small unmanned balloons [5]. The radio signals giving the altitude and temperature of the apparatus, and the ultraviolet solar intensities, are received and recorded graphically at a fixed ground station $[5,6,7]$.

As mentioned in the previous paper [1], the problem then was (and still is) the lack of a satisfactory photoelectric cell for measuring the incident solar ultraviolet radiation, which increases rapidly in intensity and changes markedly in spectral quality, as the apparatus rises above the earth's surface and passes through the layer of ozone that is concentrated principally in the stratosphere.

The type of photoelectric cell now available commercially, best suited for this work, consists of a spherical bulb covered with a diffusing window; the interior of the bulb being photoelectrically sensitized with a suitable metal $(\mathrm{Cd})$ which, in the samples used, changed in spectral response and intrinsic sensitivity with age, and with temperature, to a greater extent than is desirable. ${ }^{2}$

One of these photoelectric cells ( $\mathrm{Cd}-38303)$ had a unique record of performance. It made three stratosphere flights $(1938,1939$, and 1940), and was used in measuring sky and solar radiation at Flagstaff, Ariz., in 1938. In its flight of June 20, 1940, after attaining an altitude of $83,000 \mathrm{ft}(25 \mathrm{~km})$, the radio sonde descended to an elevation of $70,000 \mathrm{ft}(21 \mathrm{~km})$, where it floated for several hours and was carried out to sea. The following day, at sunset, it was seen falling into the sea with three of the original six balloons still inflated, some 140 miles southeast of the Boston Lightship, and was recovered soon thereafter. The report received with the return of the instrument, a month later, stated: "On delivery at Fish Pier, Boston, box was badly broken, contents loosened from fastenings; but (radio) tubes not broken. Batteries, (barograph, motor, filters) were missing."

It is interesting to note that the spectral response of $\mathrm{Cd}-38303$ (as indicated by the transmissions of four filters [17], using a Mazda $C X$ lamp as a source of ultraviolet) before the flight of 1940 was the same as before the flight of 1939. Similarly, the spectral response after the flight of 1940 was the same as after the flight made in 1939. In both years the percentage transmissions of ultraviolet through these filters was lower (indicating a higher spectral response in the short wavelengths relative to the long wavelengths) after the flight than before the flight, with an apparent recovery in relative spectral response after resting a year. Similar changes in spectral response were observed in other cadmium-photoelectric cells after a flight. A correction for this change in filter transmission, which is similar in magnitude but opposite in direction to the correction for temperature, has not been applied to the herein described ultraviolet measurements, because it is small and because of the lack of knowledge as to when the change occurred during a flight.

\footnotetext{
${ }^{2}$ In this connection, we record our appreciation of the assistance of Dr. Louis Koller, of the Research Laboratory of the General Electric Company, in selecting photoelectric cells that had closely the spectral range of sensitivity desired in this investigation. We thank also the National Geographic Society and the Radio Section of the National Bureau of Standards for their cooperation in this work.
} 


\section{TESTS WITH THE NEW TYPE RADIO TUBES}

In view of the fact that the highest elevation attainable is limited by the kind of balloons used and by the weight of the apparatus that is being transported, preliminary to the flights of 1940 an attempt was made to reduce the weight by employing smaller batteries and radio tubes than were previously used in the ultraviolet meter [1, 5, 7].

At the outset it was found that the small radio tubes, recently introduced for use in hearing aids, were unsuitable for operation in the stratosphere ultraviolet meter.

Several radio units were assembled using some of the new 1.4-volt radio tubes (principally the types $1 \mathrm{~N} 5-\mathrm{GT}, 1 \mathrm{~A} 7-\mathrm{GT}$, and $1 \mathrm{G} 6-\mathrm{G}$ ), in an attempt to decrease the weight of the apparatus. However, since the battery requirements were similar to those used with the older type of radio tubes, the actual saving in weight in the ultraviolet meter was only about 4 ounces.

The 1N5-GT tubes operated satisfactorily, and were incorporated in some of the amplifiers used in 1940. However, none of the combinations of the other new models of radio tubes investigated operated as satisfactorily as those previously employed in the transmitters, and their use without further prolonged experiments was considered inexpedient, especially since there would have been but little reduction in weight of the radio sonde.

\section{EXPLORATION OF THE VERTICAL DISTRIBUTION OF OZONE IN THE STRATOSPHERE}

Reference has already been made to earlier papers [1, 5, 6, 7] for a description of apparatus and methods of measurement of ultraviolet solar intensities in the stratosphere.

The balloon flights of 1939 differed from those made in 1940 only in that, in the latter, additional equipment in the form of an electrolytic resistor $[2,3]$ was included to measure the ambient temperature of the photoelectric cell and filters. This temperature element was near the center of the axis of rotation of the disk that supported the filters, and hence measured the temperature of the enclosure under the disk and the cover of the box containing the ultraviolet meter (see fig. 6 of RP1207 [1]). As in previous years, the top of the box ("cover") was painted black to heat the interior by absorbing solar radiation. The sides and bottom of the box were wrapped in cotton batting and black cloth to retard cooling of the batteries. An extension arm, attached to the axis of rotation of the disk that supports the filters, provided a means for opening the electric circuit of the ultraviolet meter and closing the circuit through the temperature element. In order to eliminate interference between the radio signals indicating the ultraviolet intensities, and the temperature signal, all the filters and screens were placed close together on one side of the disk, leaving about one-half the disk opaque (see fig. 6, of RP1207 [1]). As this opaque part of the disk passed over the window of the photoelectric cell, two records per revolution of the disk were obtained of the reference frequency of the ultraviolet meter (see figs. 8 and 9, RP1207 [1]); and when the temperature element was in the circuit, two intervening frequency measurements were recorded, giving the temperature. Since the disk made one revolution in about 45 seconds, and the rate of ascent was 700 to 
$1,000 \mathrm{ft} / \mathrm{min}$, numerous measurements were obtained of the ultraviolet solar intensity and of the temperature of the enclosure at various elevations above the earth's surface.

\section{NOTES ON THE STRATOSPHERE BALLOON FLIGHTS}

In the flights of 1939, the weight of the complete apparatus was about $5 \mathrm{lbs}(2.3 \mathrm{~kg})$. In the flights of 1940, the additional weight of the temperature element was compensated by reducing the length of the rubber shock cord. In all the flights latex balloons, model 700 (weight 700 to $740 \mathrm{~g}$ ), made by the Dewey and Almy Chemical Co., were used. These balloons were joined in tandem by means of especially strong long-staple cotton twine (regular twist, mainsail stitching twine; 12S/14 ply; weight $130 \mathrm{ft} / \mathrm{oz}$ ) having a minimum breaking strength of $30 \mathrm{lbs}(14 \mathrm{~kg})$. To provide a long period of pendular swing, the distance between the box containing the ultraviolet meter and the point of attachment of the lowest balloon was 30 to $32 \mathrm{~m}$. This suspension cord consisted of three strands of twine having a minimum breaking strength of $90 \mathrm{lbs}$, which was needed when launching the apparatus in a strong wind.

The distance between the points of attachment of the individual balloons was $8 \mathrm{~m}$; the sections being graded from three strands for the lower three balloons to one strand each for the two topmost balloons. Each balloon was held to the main lifting cord by a 5 -m length of this twine.

In some of the flights provision was made for releasing the balloons after bursting, as described by Johnson [13]. However, the device usually became entangled with the main lifting cord and failed to drop off. Moreover, in all recoveries of apparatus, the main part of the balloon was blown into long narrow strips $(0.5$ to $2.5 \mathrm{~cm}$ wide; 0.5 to $1.5 \mathrm{~m}$ long) that sometimes became entangled in the lifting cord, and only the heavy tube at the end (weighing about 1.5 to $2 \mathrm{oz} ; 40$ to $60 \mathrm{~g})$ remained. The additional "dead" weight on the bursting of one balloon, therefore, had but little effect upon the flight of the apparatus, which is determined by the lifting power of the remaining balloons. Hence, this refinement in making flights was not continued.

All of the ascents were made at Beltsville, Md. In 1939 three flights were made, and there were three recoveries. In the first flight (June 22), using Cd-38303, two balloons were lost soon after the start; therefore it was a four-balloon ascent, to $78,000 \mathrm{ft}$, at the rate of about $630 \mathrm{ft} . / \mathrm{min}$. The descent by two balloons began at 1:00 p. m. The radio sonde was seen falling into Chesapeake Bay, near Baltimore, from which it was recovered about $4 \mathrm{p}$. $\mathrm{m}$.

In the second flight (June 26, to a height of 78,000 ft), the ascent was at the rate of $1,325 \mathrm{ft} / \mathrm{min}$ with six balloons; then $875 \mathrm{ft} / \mathrm{min}$ with five balloons; then $550 \mathrm{ft} / \mathrm{min}$ with four balloons-descent on three balloons.

In the third flight (July 1, 1939) using seven balloons, each having a free lift of $1 \mathrm{lb} 14 \mathrm{oz}$, a height of $87,000 \mathrm{ft}$ (perhaps $89,000 \mathrm{ft}$ ) was attained-one-balloon descent. The rate of ascent was $920 \mathrm{ft} / \mathrm{min}$ to an elevation of $70,000 \mathrm{ft}$, then $670 \mathrm{ft} / \mathrm{min}$. The ascent started at $10: 40 \mathrm{a} . \mathrm{m}$. and the descent at $12: 43 \mathrm{p} . \mathrm{m}$. The apparatus was recovered at 2:10 p. m. near Middletown, Del., a distance of about 70 miles from the starting point. In the two previous flights, the 
apparatus was recovered in nearby Maryland and Virginia, respectively.

In 1940, four ultraviolet radio sonde flights were made, only three of which were successful. In each flight six balloons were used, each balloon being inflated to lift $1 \mathrm{lb} 14 \mathrm{oz}$. In the fourth flight (June 27), one balloon became detached during the launching; hence it was a five-balloon ascension.

The first flight (June 17) was unsuccessful because of local radio interference, and the radio transmitter may have been injured in launching the apparatus. The apparatus was recovered the following morning by a coast guard on Cape Henlopen Beach, N. J.-three balloons intact, box crushed. Apparently the partly inflated balloons had dragged the box along the shore, breaking all the apparatus.

In the second flight (June 20), using Cd-38303, the ascent began at $10: 59 \mathrm{a} . \mathrm{m}$. in a strong breeze. The maximum elevation $(83,000 \mathrm{ft})$ was attained at $12: 47$ p. m. The descent was followed until 4:30 p. m., when the sun was too low to shine upon the ultraviolet meter but seemed to heat it (see fig. 1). The flight record is interesting in that the measurements of ultraviolet intensities at the ceiling give a more sharply defined indication of the time the highest elevation was attained than the barograph record. As mentioned on a preceding page, during the descent the apparatus floated for some hours at an elevation of about $70,000 \mathrm{ft}$, and was blown out to sea beyond Boston, where it fell into the ocean 24 hours later. Whether the box of apparatus was broken on the shoals, or by grappling hooks in making the recovery, was not learned. As already noted, in the flights of 1939 this photoelectric cell fell into Chesapeake Bay.

In the third flight (June 22) the ascent started at 10:30 a. m. The maximum elevation $(87,300 \mathrm{ft}$ ) was attained at $12: 25 \mathrm{p} . \mathrm{m}$. In this flight, as in the preceding one, the rapid change in ultraviolet intensities with elevation gave a more sharply defined indication of the time the maximum elevation was attained than the barographic record. In this flight and in the following one there was no recovery of apparatus. Presumably this was owing to (upper air) weather conditions which were unusual, in that there were but few clear days all summer; and presumably, also, owing to the fact that the balloons did not descend promptly the same day (or in the daytime) when the descent could be seen. Nevertheless, as a whole, the score of recoveries of apparatus (14 recoveries out of 19 flights; 74 percent in 4 years) seems remarkably high, considering the fact that the flights were made so close to large bodies of water, marshy areas, and infrequently visited lowland covered with trees and underbrush. Of the 14. recoveries, three were from the water and two on the beach, bordering large bodies of water.

\section{EVALUATION OF THE ULTRAVIOLET INTENSITY MEASUREMENTS}

For details regarding the methods of evaluation of these measurements, reference is made to preceding papers $[1,5,6]$. It will, therefore, suffice to recall that the evaluation of solar ultraviolet intensities in the stratosphere requires a knowledge of: (a) the spectral-response curves of the photoelectric cell; (b) the spectral ultraviolet transmission of the filters; (c) the spectral-absorption coefficients of ozone 
and Rayleigh scattering; (d) the solar-energy curve outside the atmosphere; and (e) the change in transmission of the integrated ultraviolet solar radiation, resulting from a change in temperature of the photoelectric cell and filters used in the ultraviolet meter. The latter enters as a minor correction in the calculations.

\section{EFFECT OF TEMPERATURE ON THE ULTRAVIOLET MEASUREMENTS}

The effect of temperature on the ultraviolet solar-radiation measurements was determined by enclosing an ultraviolet meter in a heatinsulated, airtight box that was cooled with solid $\mathrm{CO}_{2}$ ("dry ice"). The source of ultraviolet was a tungsten Mazda $C X$ lamp, operated under conditions to give filter transmissions of integrated ultraviolet radiation closely similar to those obtained in measuring ultraviolet solar radiation in the stratosphere (see fig. 2 of reference [11]).

Starting with the apparatus at room temperature $\left(25^{\circ} \mathrm{C}\right)$, filter transmissions were made at decreasing temperatures, down to $-40^{\circ} \mathrm{C}$. By this procedure the apparatus was always warmer than the refrigerant, and no moisture condensed on the windows and the filters.

In the temperature range of $+25^{\circ}$ to $-35^{\circ} \mathrm{C}\left(\Delta=60^{\circ} \mathrm{C}\right)$ the filter transmissions increased by 2.1 to 2.8 percent (average 2.5 percent for all photocells) of the value observed at room temperature. For example, using photoelectric cell Cd-38303, the transmissions of the $L G$-filter increased from 21.0 to 23.8 percent and the LS-filter increased from 42.2 to 45.0 percent ( $\Delta=2.8$ percent).

This is equivalent to a decrease in spectral sensitivity of the photoelectric cell in the short wave lengths (or increase in sensitivity in the long wavelengths with decrease in temperature), or an increase in spectral transmission of the filters in the short wavelengths as observed by Arrol [18]. The combined effect of these two elements is the opposite of the change in spectral quality of the ultraviolet (increase in intensity in the short wavelengths, producing a decrease in percentage transmission of the filters) observed with increase in elevation above the earth's surface. This correction is small, however; and, because of the rise in temperature (see fig. 1), is practically negligible at the highest elevations. This test for change in spectral response is extremely sensitive and easily observed. The change in total response (intrinsic sensitivity) was too small to separate from the errors of measurement of the total intensity.

In figure 1 are depicted the measurements of the ambient temperature of the photoelectric cell and the filters, observed on two flights into the stratosphere. It is interesting to note that the lowest temperatures $\left(-15^{\circ} \mathrm{C}\right)$ within the box occurred at an elevation of $15 \mathrm{~km}$, which was the starting point in the calculations of our earliest measurements $[5,6]$ and is the beginning of an appreciable change in concentration of ozone per kilometer as shown in figure 5.

Incidentally, it is relevant to note that, relative to the large variations in the intensity measurements, the corrections for temperature are small (largest at 12 to $16 \mathrm{~km}$ ), so that by a fortuitous combination of data on spectral response of the photocells and transmissions of the filters, used in the stratosphere measurements of 1938, the graph (fig. 14 of RP1207 [1]) showing the distribution of ozone at various elevations above the earth's surface is in good agreement with subsequent observations (see fig. 5). 


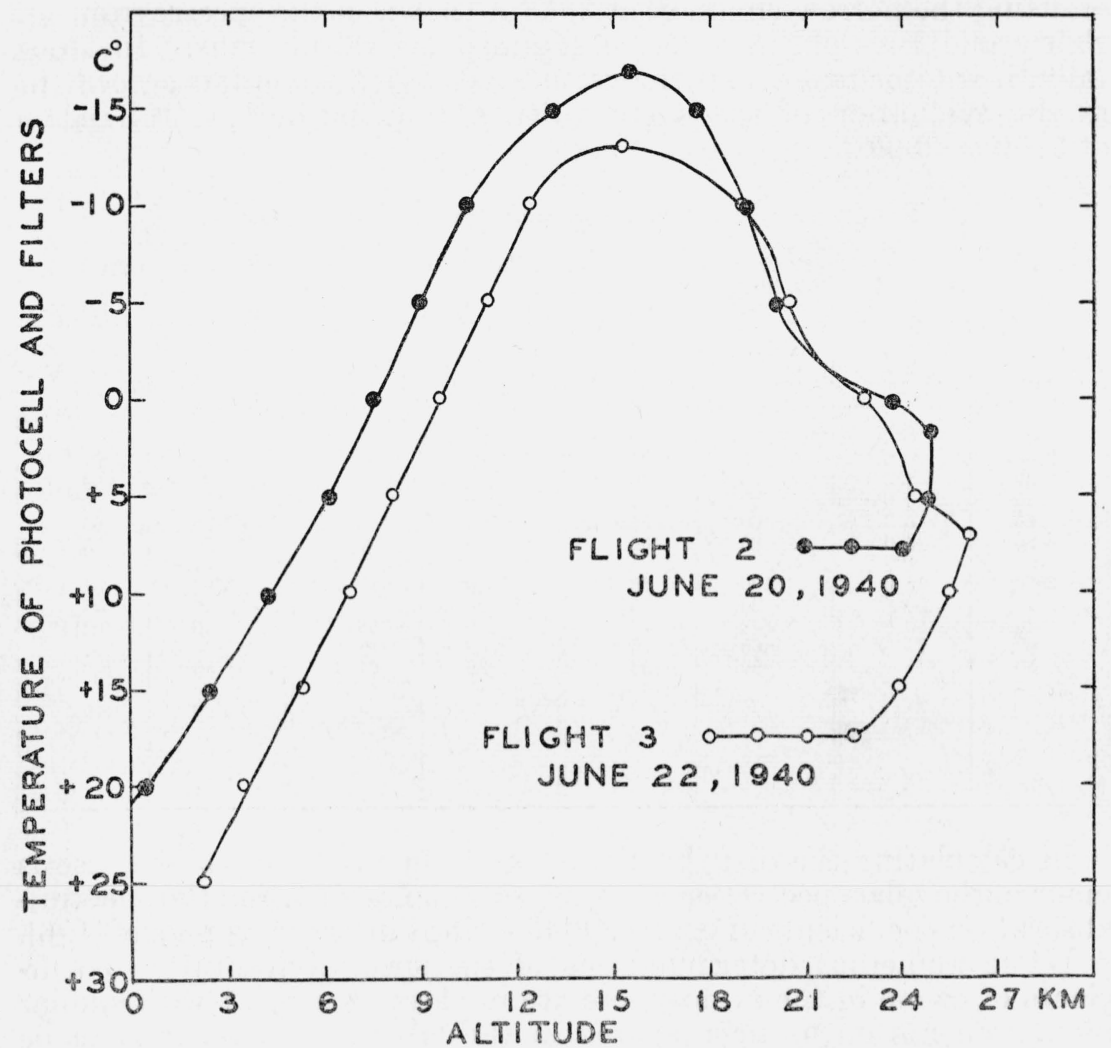

FIGURE 1.-Variation in temperature of ultraviolet meter with altitude.

2. THE EXTRATERRESTRIAL ULTRAVIOLET SOLAR SPECTRALENERGY CURVE

An important factor that enters into the calculations of the ozone distribution above the apparatus is the shape of the curve depicting the solar spectral-energy curve of wavelengths shorter than about $3200 \mathrm{~A}$, outside the earth's atmosphere. The solar spectrograms and spectrum photographic density measurements of Fabry and Buisson [12] show large Fraunhofer bands in the region of 2900, 2940, 3025, and $3120 \mathrm{~A}$, with two bands of high intensity in the region of 2985 and $3055 \mathrm{~A}$, respectively. The early measurements of Pettit, using integrated sunlight, indicated a high emission in the region of $2980 \mathrm{~A}$; but this was not observed on the center of the solar disk [4]. All our measurements by means of photoelectric cells and filters [14, 11] indicate a high emission in the region of $2980 \mathrm{~A}$. A blueprint of unpublished observations by Brian O'Brien (given us in 1930) shows a high emission in the region of $2950 \mathrm{~A}$ and a low emission at $3030 \mathrm{~A}$.

In view of these uncertainties, and in order to obtain calculated filter transmissions that are in agreement with the observed filter transmissions of the integrated ultraviolet incident upon the photoelectric cell, we adopted a spectral-energy distribution that is high in the region of $2980 \mathrm{~A}$ (see table 1) and low in the region of $3050 \mathrm{~A}$ - 
omitting the narrow emission at $3055 \mathrm{~A}$ shown in the spectrograms of Fabry and Buisson, in order to simplify the calculations. Incidentally, it is to be noted that the various observers are in fair agreement in the evaluation of the energy distribution in the spectral region of 3100 to $3300 \mathrm{~A}$.

\section{TABLE 1.-Solar energy outside the earth's atmosphere}

[From all data available: Pettit (integrated and center of disk, 1931-39); Fabry and Buisson (1922); O'Brien (unpublished 1930, blueprint); Coblentz and Stair (1935); Stair and Hand (1939)]

\begin{tabular}{|c|c|c|c|c|c|c|c|}
\hline $\begin{array}{l}\text { Wave- } \\
\text { lengths }\end{array}$ & Energy & $\begin{array}{l}\text { Wave- } \\
\text { lengths }\end{array}$ & Energy & $\begin{array}{l}\text { Wave- } \\
\text { lengths }\end{array}$ & Energy & $\begin{array}{l}\text { Wave- } \\
\text { lengths }\end{array}$ & Energy \\
\hline $\begin{array}{r}A \\
2800 \\
20 \\
40 \\
60 \\
80\end{array}$ & $\begin{array}{l}0.5 \\
1.3 \\
3.0 \\
5.3 \\
9.0\end{array}$ & $\begin{array}{c}A \\
3000 \\
20 \\
40 \\
60 \\
80\end{array}$ & $\begin{array}{l}75 \\
70 \\
54 \\
54 \\
56\end{array}$ & $\begin{array}{r}A \\
3200 \\
20 \\
40 \\
60 \\
80\end{array}$ & $\begin{array}{l}90 \\
93 \\
95 \\
96 \\
97\end{array}$ & $\begin{array}{c}A \\
3400 \\
20 \\
40 \\
60 \\
80\end{array}$ & $\begin{array}{l}97.0 \\
96 \\
96 \\
96 \\
96.5\end{array}$ \\
\hline $\begin{array}{r}2900 \\
20 \\
40 \\
60 \\
80\end{array}$ & $\begin{array}{l}15.0 \\
30 \\
60 \\
73 \\
75\end{array}$ & $\begin{array}{r}3100 \\
20 \\
40 \\
60 \\
80\end{array}$ & $\begin{array}{l}60 \\
66 \\
72 \\
76 \\
83\end{array}$ & $\begin{array}{r}3300 \\
20 \\
40 \\
60 \\
80\end{array}$ & $\begin{array}{l}97.5 \\
98 \\
98 \\
98 \\
97.5\end{array}$ & $\begin{array}{r}3500 \\
20 \\
40 \\
60 \\
80 \\
\\
3600 \\
\\
3700\end{array}$ & $\begin{array}{r}97 \\
98 \\
100 \\
103 \\
106 \\
\\
110 \\
112\end{array}$ \\
\hline
\end{tabular}

In calculating the distribution of ozone in the stratosphere, use is made of the solar spectral-energy data given in table 1, and the spectralabsorption coefficients of ozone [16] described in previous papers $[1,6]$.

While numerous determinations of the spectral-absorption coefficients of ozone in the atmosphere are in close agreement with similar measurements on ozone prepared in the laboratory [15], it is to be noted that recent investigations by Adel and Lampland [8] seem to indicate the presence of oxides of nitrogen $\left(\mathrm{N}_{2} \mathrm{O}\right.$ and $\left.\mathrm{N}_{2} \mathrm{O}_{5}\right)$ in the upper atmosphere [9], produced by the photochemical action of ultraviolet solar radiation. Adel [9] points out that, if the coincidence of the bands of selective absorption (at 7.77 and $8.57 \mu$, respectively) in the atmosphere and of laboratory preparations of the abovementioned oxides of nitrogen is not fortuitous, there would appear to be a layer of $\mathrm{N}_{2} \mathrm{O}$, comparable to the known layer of ozone, in the stratosphere. Such a deduction has wide implications. The writers do not recall data on the ultraviolet spectral absorption of $\mathrm{N}_{2} \mathrm{O}$. The measurements of Jones and Wulf [10] show no bands of selective absorption of $\mathrm{N}_{2} \mathrm{O}_{5}$ in the ultraviolet; but an increase in absorption with decrease in wavelength is recorded, the spectral-absorption coefficients being similar in magnitude to those of ozone. It is therefore an interesting scientific question how much of the observed ultraviolet spectral absorption is caused by each of these gases $\left(\mathrm{O}_{3}, \mathrm{~N}_{2} \mathrm{O}\right.$, $\mathrm{N}_{2} \mathrm{O}_{5}$ ); though for our purposes it seems relatively unimportant, since use is made of the directly observed spectral-absorption coefficients that appear to be representative of all of the gases that form the absorbing layer in the stratosphere.

To recapitulate, using sunlight, also starlight [15], as a source, measurements show narrow bands of selective absorption superposed upon a wide band of general absorption in the terrestrial atmosphere, that increases with decrease in wavelength in the extreme ultraviolet 
of the solar-energy spectrum. Earlier measurements of these atmospheric ultraviolet-absorption coefficients have been correlated with definite amounts (n. t. p.) of laboratory preparations of ozone. Recent infrared solar spectral-energy measurements show (atmospheric) absorption bands identifiable with laboratory preparations of certain oxides of nitrogen. If this is not a fortuitous, approximate, coincidence (because of the small dispersion usable) of Fraunhofer

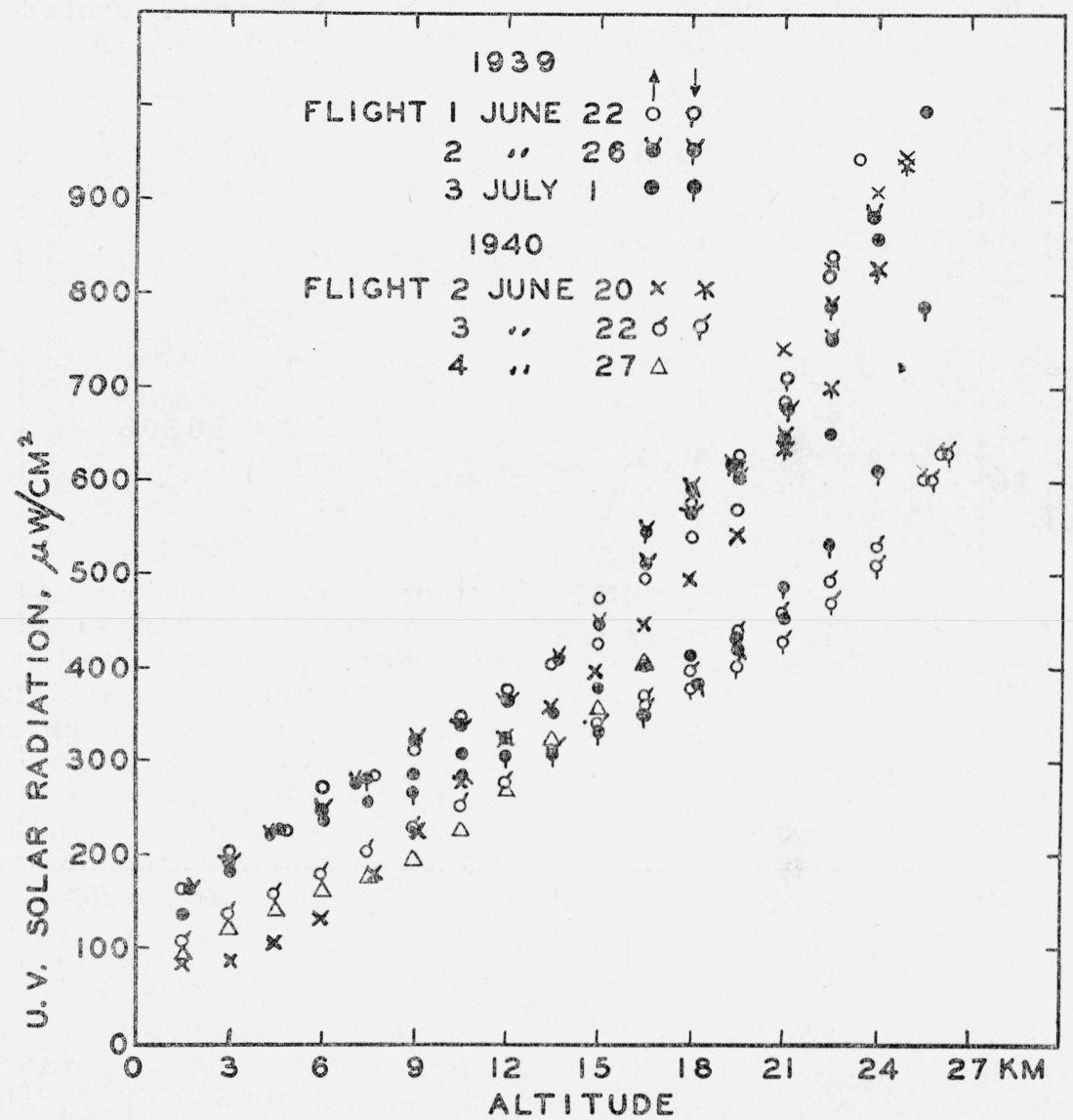

FIGURE 2.-Integrated ultraviolet solar and sky radiation intensities of wavelengths shorter than $3132 A$ at various altitudes above the earth's surface.

lines, the presence of oxides of nitrogen in the upper atmosphere is to be inferred, and is to be expected on the basis of ultraviolet photochemical action. However, these deductions and inferences do not modify the herein-described measurements and conclusions, which pertain to the position, and not the composition of the absorbing layer, in the stratosphere.

\section{EXPOSITION OF DATA}

The ultraviolet intensities are received at the ground station in the form of a graphical record of audio frequencies emitted by the photoelectrically controlled radio transmitter, during ascent and descent of 
the apparatus, as shown in figure 8 of the preceding paper [1]. From such records of ascents in 1939 and 1940, data are obtained showing the variation in ultraviolet solar intensity with altitude, as depicted in figures 9 and 10 of the preceding paper [1].

In figure 2 are depicted the integrated ultraviolet intensities of ultraviolet solar radiation of wavelengths shorter than $3132 \mathrm{~A}$, at various elevations above sea level, observed in 1939 and in 1940. At the lower elevations the wide spread in the intensity measurements is to be attributed to clouds, haze, and dust on different days. At the

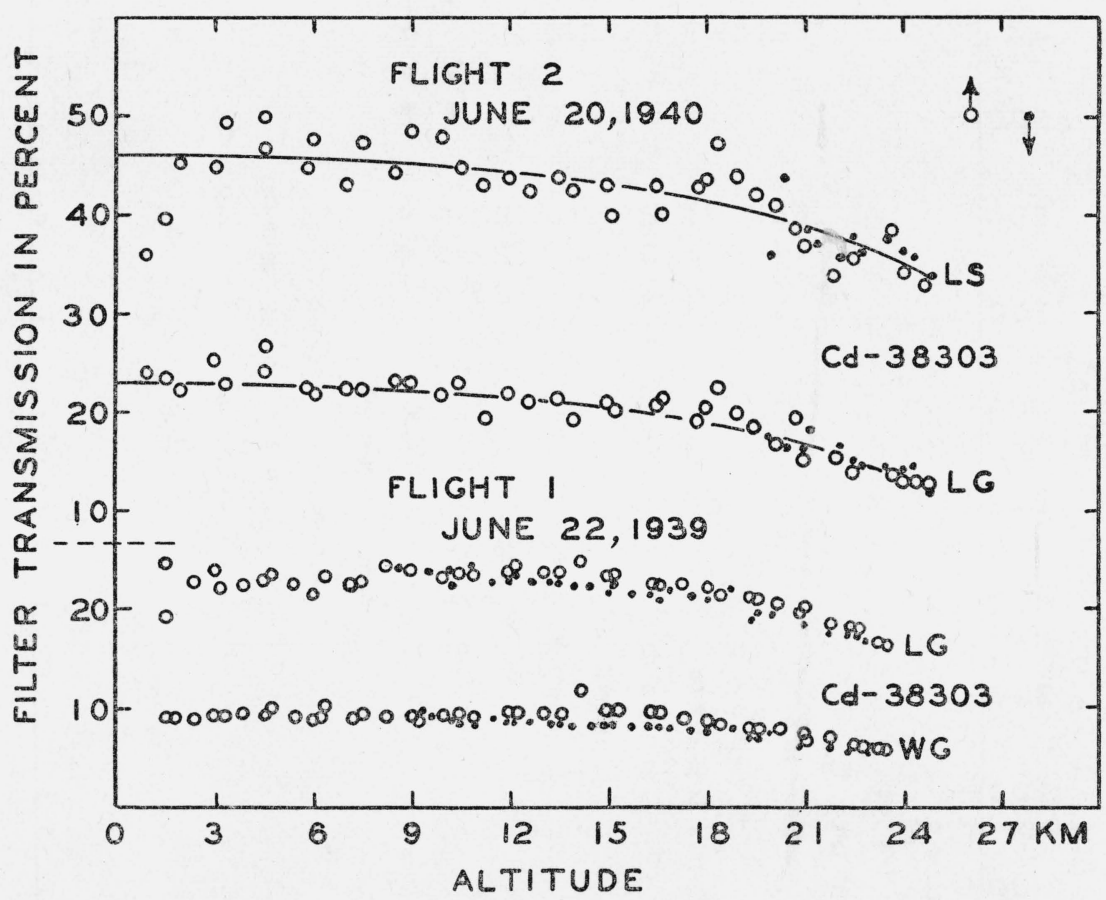

Figure 3.-Percentage transmission of the glass filters used in various stratosphere flights.

highest elevations the ultraviolet intensities observed in 1939 and in 1940 are in good agreement with the measurements of 1938, indicating an intensity of about $900 \mu \mathrm{W} / \mathrm{cm}^{2}$ of ultraviolet radiation of wavelengths shorter than $3132 \mathrm{~A}$, at an altitude of about $27 \mathrm{~km}$ [1].

From data similar to those depicted in figures 9 and 10 [1], the filter transmissions are calculated by two methods as 'outlined on page 599 and depicted in figure 11 of the preceding publication [1]. Some of these filter transmissions, observed at different elevations of the ultraviolet meter, using photoelectric cell $\mathrm{Cd}-38303$, are plotted in figure 3 . The arrows in the upper right-hand corner of this illustration indicate the ascent and descent of the apparatus. In order to increase the accuracy of the audio-frequency readings, the glass filters used in the flights of 1940 had higher integrated ultraviolet transmissions than those used in 1938 and in 1939. Using the same photoelectric cell (Cd-38303), it may be noted that the individual observations of 1940 suffered greater variations than those obtained with this apparatus 
during the two preceding years. In the case of this particular photoelectric cell this variation may have been caused partly, perhaps, by variation in contact resistance of the electrode with the photosensitive surface, which seemed to vary somewhat after recovery of the apparatus, in 1940 .

These filter transmissions at different elevations have been corrected for temperature, see figure 1. From these filter-transmission curves [16] the amount of ozone traversed at a given height above the earth's

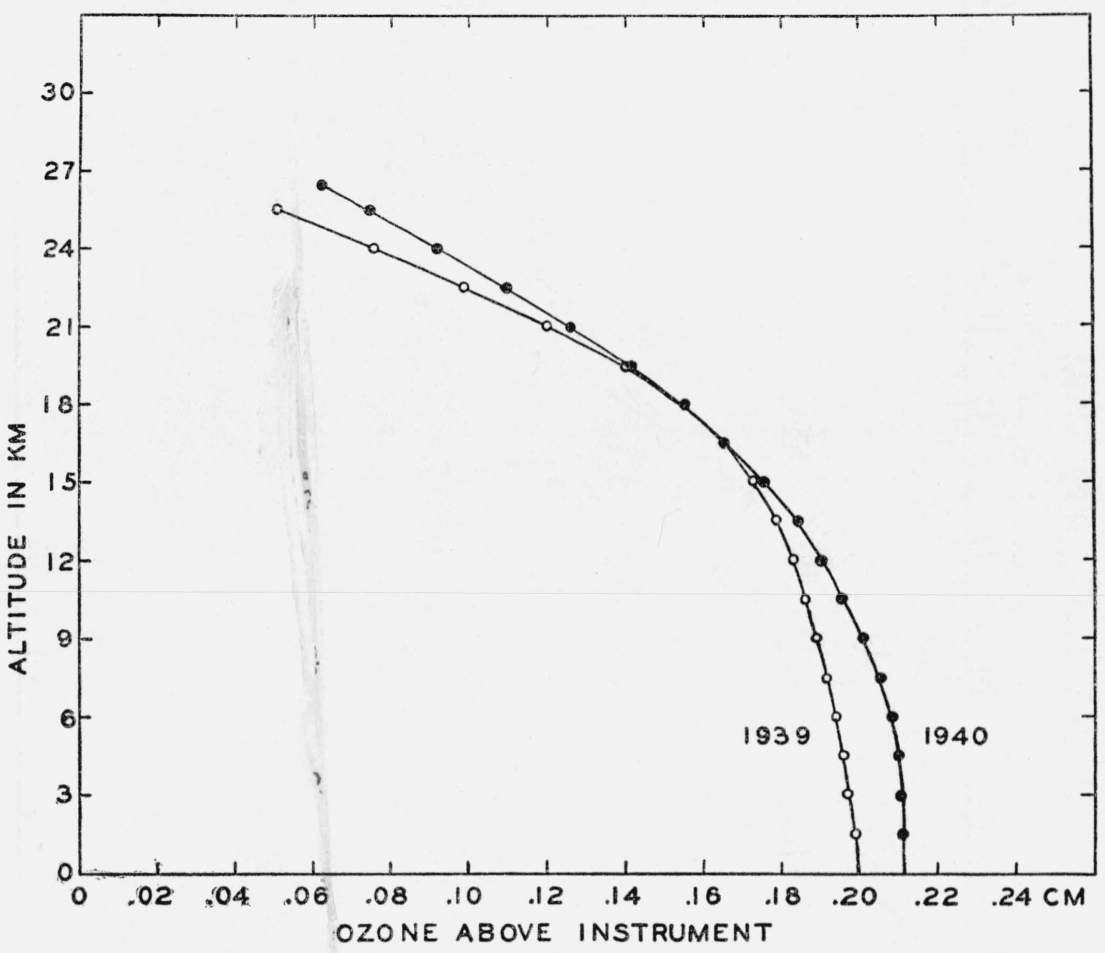

FIGURE 4.-Graphs showing the amount of ozone above the ultraviolet-intensity meter, at various heights above the earth's surface, observed in the flights of 1939 and 1940 .

surface is then calculated, as outlined on page 602 of the previous paper [1].

In figure 4, curves are depicted showing the amount of ozone above the ultraviolet-intensity meter, at various heights above the earth's surface. The graph for 1939 is the average of three flights, and that of 1940 is the average of two flights (see fig. 2 for the dates of the flights). Owing to the difficulties in making such observations, the difference between the single curves and the average of the two curves, at any elevation, is not sufficiently marked to be considered real.

Following the procedure previously outlined (p. 604 [1]), from figure 4 is derived the amount of ozone per kilometer $\left(\mathrm{O}_{3} / \mathrm{km}\right)$ at different elevations above the earth's surface. 


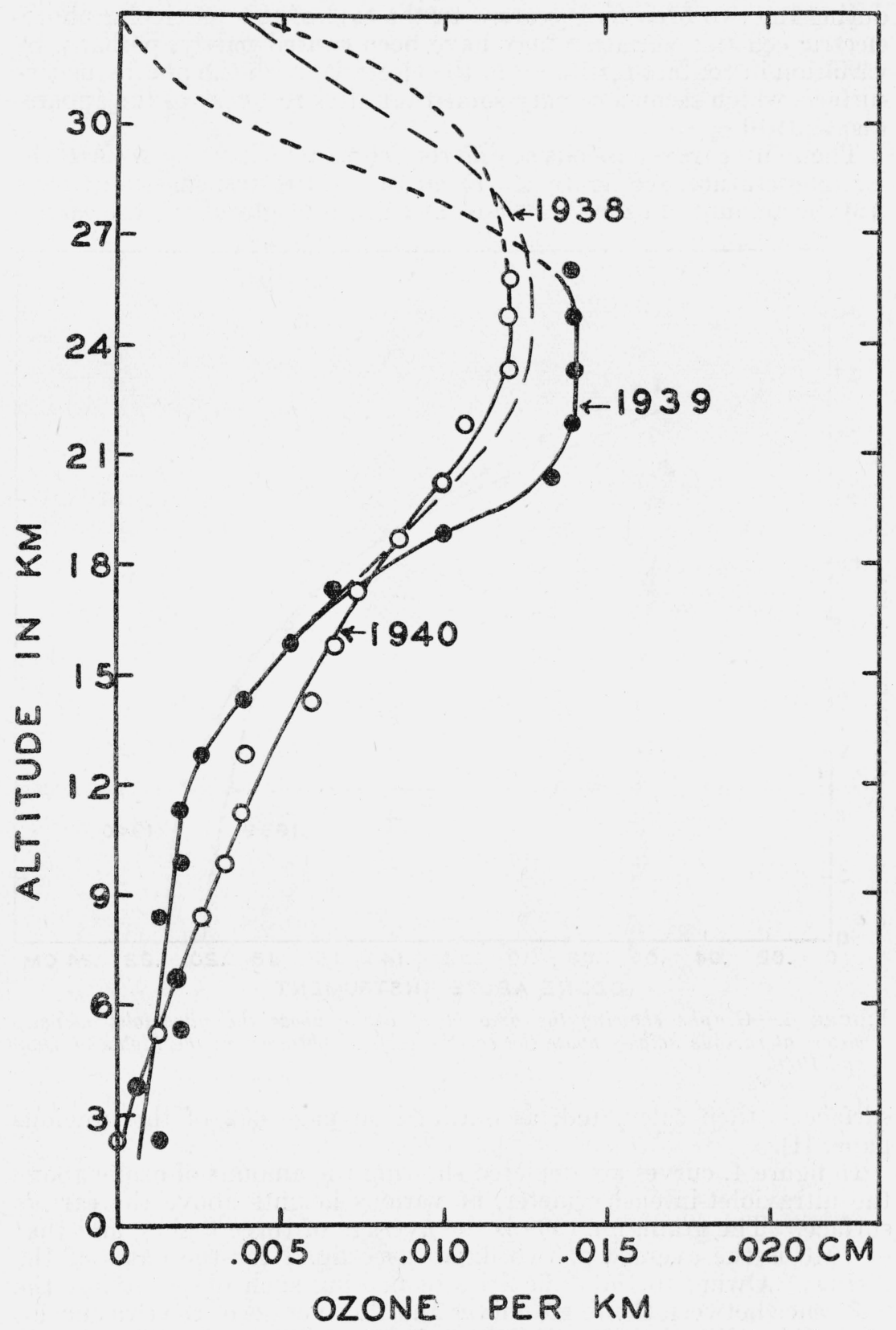

FIGURE 5.-Graphs showing the distribution of ozone at various elevations above the earth's surface. 
As shown in figure 5, the relatively high concentration of ozone may perhaps have extended to lower elevations $(12 \mathrm{~km})$ in 1940 than in 1939. In this illustration is depicted also the curve obtained in 1938, after correcting the filter transmission for changes in temperature of the apparatus during the flights. The explorations of all three seasons are in good agreement in placing the maximum concentration of the ozone at a height of 23 to $25 \mathrm{~km}$. The dotted part of these curves shows the distribution of ozone required to account for the 30 to 35 percent of ozone that still remained above the apparatus when it was at an elevation of about $27 \mathrm{~km}$ above sea level.

\section{REFERENCES AND NOTES}

[1] W. W. Coblentz and R. Stair, Distribution of ozone in the stratosphere, J. Research NBS 22, 573 (1939) RP1207.

A complete report of the stratosphere flights, and of ultraviolet measurements at Flagstaff, Ariz. (elevation 7,300 ft) in 1938.

[2] D. N. Craig, Electrolytic resistors for direct-current applications in measuring temperature, J. Research NBS 21, 225 (1938) RP1126.

[3] H. Diamond, W. S. Hinman, F. W. Dunmore and E. G. Lapham, An improved radio sonde and its performance, J. Research NBS 25, 327 (1940) RP1329; also RP1082 (1938).

See figure 5 for electrolytic temperature-measuring element, samples of which were supplied us by Julien P. Friez \& Sons, Inc., Baltimore, Md.

[4] E. Pettit, Spectral energy curve of the sun in the ultraviolet, Astrophys. J. 91, $159(1940)$.

[5] W. W. Coblentz and R. Stair, A radiometric method of measuring ultraviolet solar-radiation intensities in the stratosphere, Bul. Am. Meteorolog. Soc. 18, 345 (1937); Radiologica 1, 12 (1937). See also J. Research NBS 17, 1 (1936) RP899.

A brief description of the methods used and a preliminary report of the results obtained in the stratosphere flights of 1937.

[6] R. Stair and W. W. Coblentz, Radiometric measurements of ultraviolet solar intensities in the stratosphere, J. Research NBS 20, 185 (1938) RP1075.

Complete report of the results of the stratosphere flights of 1937 .

[7] R. Stair, A precision radio instrument for transmitting measurements of ultrauiolet intensities from unmanned balloons to a ground station, J. Research NBS 22, 295 (1939) RP1181.

A description of improvements in the radio sonde previously used [5, 6]. By combining a balanced direct-current amplifier [RP647] with a relaxation oscillator and short-wave transmitter similar to that developed by Diamond and his collaborators (RP1082 [3]) measurements of ultraviolet intensities are obtained to the highest altitudes attained by the radio sonde [1].

[8] A. Adel and C. O. Lampland, $A$ new band in the absorption spectrum of the earth's atmosphere, Astrophys. J. 8\%, 198 (1938).

[9] A. Adel, Note on the atmospheric oxides of nitrogen, Astrophys. J. 90, 627 (1939).

[10] E. J. Jones and O. R. Wulf, The absorption coefficient of nitrogen pentoxide in the ultraviolet, and the visible absorption spectrum of $\mathrm{NO}_{3}, \mathrm{~J}$. Chem. Physics $5,873(1937)$.

[11] R. Stair and I. F. Hand, Methods and results of ozone measurements over Mount Evans, Colorado, Mo. Weather Rev. 6\%, 331 (1939).

[12] C. Fabry and H. Buisson, Distribution of energy in the ultraviolet of the solar spectrum, Compt. Rend. 175, 156 (1922); Astrophys. J. 54, 297 (1921). Spectrogram reproduced in J. Research NBS 15, 123 (1935) RP816.

[13] T. H. Johnson and J. G. Barry, Phys. Rev. 56, 219 (1939).

[14] W. W. Coblentz and R. Stair, Distribution of energy in the extreme ultraviolet of the solar spectrum, J. Research NBS 17, 1 (1936) RP899.

[15] F. W. P. Goetz, Die vertikale Verteilung des atmosphärischen Ozons. Ergebn. Kosmischen Physik III, 253-326, Leipzig, 1938.

An up-to-date summary of the researches on atmospheric ozone including 21 references to his own work, published since 1931. His survey of previous investigations on atmospheric ozone is published in the "Ergebnisse" I, 180-235 (Leipzig, 1931). 
174 Journal of Research of the National Bureau of Standards [Vol.26

[16] C. Fabry and H. Buisson, Data on ozone absorption, Compt. rend. 192, 457 (1931).

Ny Tsi-Ze et Choong Shin-Piaw, Compt. rend. 195, 309 (1932); 196, 916 (1933).

F. W. Paul Goetz, Ergebn. Kosmischen Physik 3, 253 (1938).

[17] W. W. Coblentz and R. Stair, Evaluation of ultraviolet solar radiation of short wave lengths, J. Research NBS 16, 315 (1936) RP877.

[18] W. J. Arrol, Change of ultraviolet transparency of glass with temperature, Nature 145, 861 (1940).

In the range of $+10^{\circ} \mathrm{C}$ to $-50^{\circ} \mathrm{C}$ the absorption coefficient was observed to increase linearly with increase in temperature.

Washington, November 1, 1940. 